\title{
A review of economic evaluation models for cardiac resynchronization therapy with implantable cardioverter defibrillators in patients with heart failure
}

\author{
F. Tomini ${ }^{1,2}(1) \cdot$ F. Prinzen ${ }^{2}$ A. D. I. van Asselt ${ }^{3,4}$
}

Received: 2 May 2015/Accepted: 25 November 2015/Published online: 4 January 2016

(C) The Author(s) 2016. This article is published with open access at Springerlink.com

\begin{abstract}
Objectives Cardiac resynchronization therapy with a biventricular pacemaker (CRT-P) is an effective treatment for dyssynchronous heart failure (DHF). Adding an implantable cardioverter defibrillator (CRT-D) may further reduce the risk of sudden cardiac death (SCD). However, if the majority of patients do not require shock therapy, the cost-effectiveness ratio of CRT-D compared to CRT-P may be high. The objective of this study was to systematically review decision models evaluating the cost-effectiveness of CRT-D for patients with DHF, compare the structure and inputs of these models and identify the main factors influencing the ICERs for CRT-D.

Methods A comprehensive search strategy of Medline (Ovid), Embase (Ovid) and EconLit identified eight costeffectiveness models evaluating CRT-D against optimal pharmacological therapy (OPT) and/or CRT-P.

Results The selected economic studies differed in terms of model structure, treatment path, time horizons, and sources of efficacy data. CRT-D was found cost-effective when compared to OPT but its cost-effectiveness became questionable when compared to CRT-P.
\end{abstract}

F. Tomini

florian.tomini@maastrichtuniversity.nl

1 Department of Clinical Epidemiology and Medical Technology Assessment, Maastricht University Medical Centre, Maastricht, The Netherlands

2 Department of Physiology, Cardiovascular Research Institute Maastricht (CARIM), Maastricht, The Netherlands

3 Department of Pharmacy, University of Groningen, Groningen, The Netherlands

4 Department of Epidemiology, University Medical Centre Groningen, Groningen, The Netherlands
Conclusions Cost-effectiveness of CRT-D may increase depending on improvement of all-cause mortality rates and HF mortality rates in patients who receive CRT-D, costs of the device, and battery life. In particular, future studies need to investigate longer-term mortality rates and identify CRT-P patients that will gain the most, in terms of life expectancy, from being treated with a CRT-D.

Keywords Review · Cost-effectiveness $\cdot$ Cardiac resynchronization therapy - Cardiac pacing . Implantable cardioverter-defibrillator - Markov chains . Models $\cdot$ Economic $\cdot$ Heart failure $\cdot$ Sudden cardiac death

JEL Classification $\quad \mathrm{C} 63 \cdot \mathrm{D} 61 \cdot \mathrm{I} 18 \cdot \mathrm{H} 43$

\section{Introduction}

Cardiac resynchronization therapy (CRT) either via a pacing device (CRT-P) or a pacemaker-defibrillator device (CRT-D) is considered an effective treatment for patients with congestive heart failure (CHF) and disturbances in heart rhythm (arrhythmias) having New York Heart Association (NYHA) class II, III and IV symptoms. Clinical trials have shown that CRT may decrease the risk of death from any cause for CHF patients by $24 \%$ during a mean follow-up time of 16 months (COMPANION study, [1]) to $36 \%$ during a mean follow-up of 29.4 months (CARE-HF study [2]). The addition of an implantable cardioverter defibrillator to the resynchronization therapy (CRT-D) can further reduce the risk of death from any cause by more than $8 \%$ (compared to CRT-P) [3], while the risk of sudden death (SCD) can be reduced by $23 \%$ [46]. However, overall costs of CRT-D are high and it is reported that about 25 to $35 \%$ of the patients do not 
respond to CRT-P [7] while implantable cardioverter defibrillators (ICDs) are not always needed to deliver the therapy [5].

A number of published economic studies have looked at the cost-effectiveness of the CRT-P and CRT-D devices for patients with CHF. The studies have mostly shown that the incremental cost-effectiveness ratios (ICERs) of CRT-D compared to optimal pharmacological therapy (OPT) alone or in combination with a CRT-P were too high due to large numbers of patients not requiring shock therapy $[8,9]$. The main aim of the present study was to critically review economic models evaluating CRT-D devices for patients with heart failure (HF), compare the structure and inputs of the cost-effectiveness models, and identify the main factors influencing the cost-effectiveness of CRT-D devices in comparison to OPT alone or in combination with CRT-P.

\section{Methods}

A systematic literature review was performed in order to identify the existing full health-economic models indexed in the main electronic databases such as Medline (Ovid), Embase (Ovid) and EconLit. The search was limited to articles published in the English language during the period from January 2000 to December 2014. The search strategies used a combination of Medical Subject Heading (MeSH) and free-text terms grouped into four categories; disease specific, device specific, economics and type of study. The relevant MeSH terms included: 'cardiac pacing, artificial', 'pacemaker, artificial', 'heart-assist devices', 'heart conduction system', 'defibrillators, implantable', 'costs and cost analysis', 'economics, hospital', 'economics, medical', 'economics, nursing', 'economics, pharmaceutical', 'costeffectiveness', 'humans'. References of the identified articles were scrutinized for additional references. Search strategies used to retrieve references from Medline (Ovid) and Embase (Ovid) are given in Annex 1.

The selection of the studies was done through pre-developed inclusion criteria. Only model-based economic evaluations (studies that included decision-tree models and Markov chain models) of implantable CRT-D devices were included. Trial-based economic evaluations were not eligible since most clinical studies have a short follow-up period while benefits of the CRT-D devices are not fully observed until the long term, and therefore we considered predictive modelling as a more valid approach to capture all costs and benefits of the therapy. All studies that were outside of the review scope, i.e. economic evaluations alongside clinical trials, reviews, meta-analyses, editorials, resource use studies or studies on costs were excluded. The first author performed the search and initial classification of the retrieved articles. All the selected articles were read independently by two reviewers (FT, ADIvA) and only those fulfilling the selection criteria were included in the review. Data extraction included: authors, year of publication, type of study and analysis, country of analysis, model structure, sources of effectiveness data, sources of economic data, sources of health state utilities, main comparators, outcomes and perspective taken as well as the main findings.

\section{Results}

\section{Search results}

The search retrieved 1839 citations, which were reduced to 1420 after excluding for duplicates and for non-English language citations. After screening titles and abstracts, 99 articles (Fig. 1), were further scrutinized to exclude papers that fell outside the scope of the review. The remaining references (15 studies) were scrutinized to include only studies on: (1) HF patients with NYHA II, III or IV, LVEF $\leq 35 \%$ [10], (2) treated with the CRT-D as a comparator and (3) that included decision-tree models or Markov chain models. The eight studies remaining [11-18] included model-based economic evaluations (i.e., Markov models and decision-tree models) of CRT-D implantations and were included for further review.

Table 1 gives the general study characteristics of the selected publications for this review. The selected studies included economic models adapting perspectives of four European health care systems (Belgium, Germany, Spain and UK) $[11-15,17,18]$ as well that of a middle income country (Brazil) [16].

\section{Modelling approaches}

All models distinguish between a short-term (represented by costs and consequences of the process of device implantation) and a long-term phase (represented by the costs and consequences of the post implementation follow-up period). The initial short-term implantation phase was generally 4 weeks while the long-term maintenance phase was the lifetime of the patient (see Table 1). Four out of the eight selected studies [13, 15-17] used a decision tree to model the short-term phase while four of the other studies [11, 12, 14, 18] included this as an initial phase into the Markov cohort models. All the selected studies [11-18] used a Markov cohort model for the long-term maintenance period.

Paths in the short-term decision trees consisted of combinations of four treatment strategies: (1) optimal medical therapy (OPT), (2) CRT-P, (3) CRT-D and (4) implantable cardioverter defibrillator (ICD). Bertoldi et al. [16] linked successful implantation of the device (CRT-P, CRT-D or ICD) to complications or no-complications after 


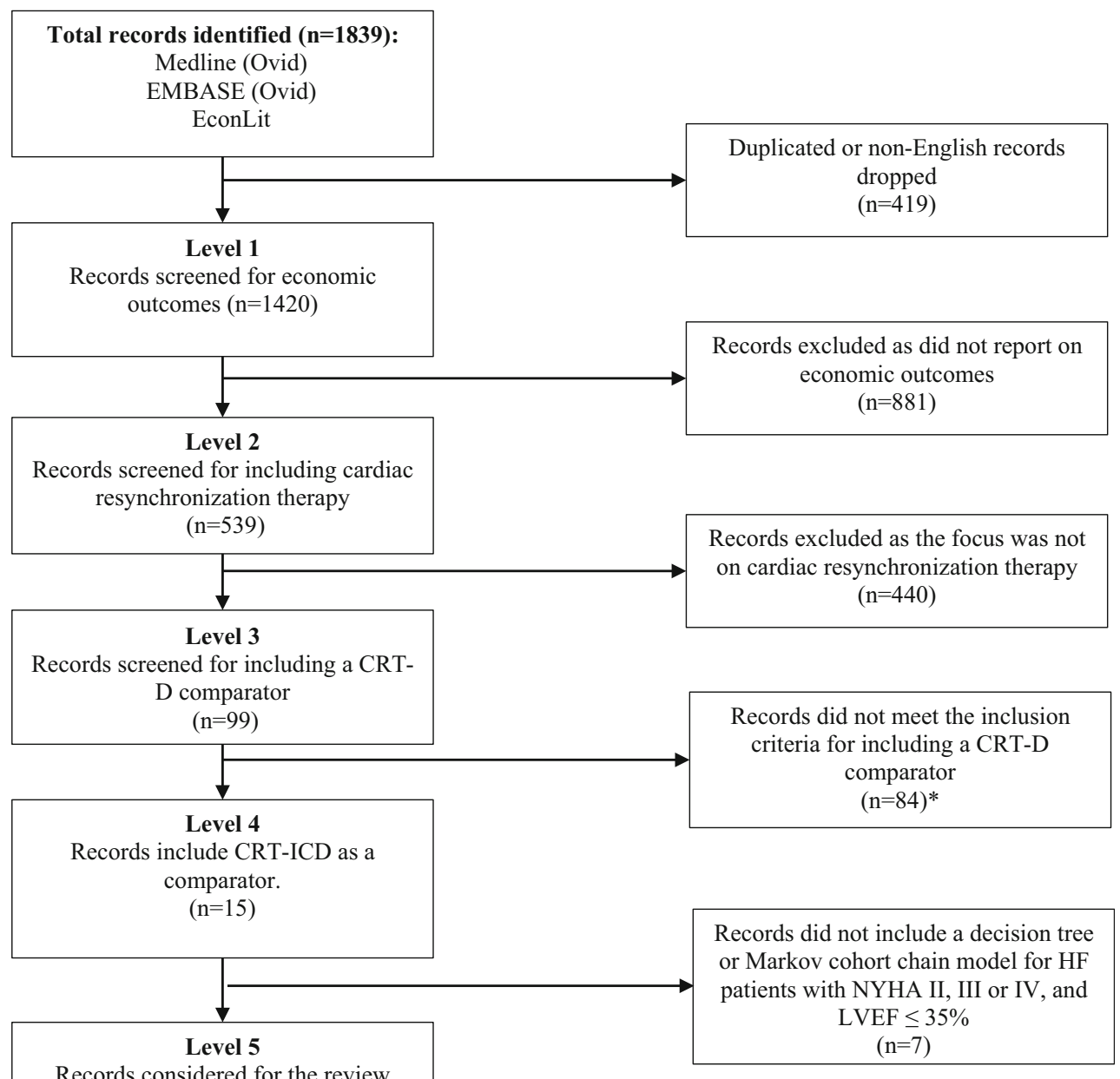

Fig. 1 The selection process *Reviews, editorials, resource use and cost studies, as well as economic evaluations alongside a clinical trial were excluded at this step. $C R T-D$, cardiac resynchronization therapy

implantation, which then led to the long-term model. Failure of implantation led to the long-term OPT strategy. This was similar to Yao et al. [12] except that these investigators allowed for up to three re-implantation attempts.

Markov states used in the eight selected studies [11-18] can be broadly classified into four categories: (1) the shortterm implantation period, (2) upgrading or switching between different implantable devices (e.g. switching from CRT-P to CRT-D), (3) the maintenance states after device implantation or when on OPT therapy; and (4) the death state. Table 2 gives a more detailed summary of these Markov states.

As mentioned, four out of the eight delected studies [11, $12,18]$ included the initial phase of the device implementation in the Markov model by adding the following states: (1) surgical intervention for CRT implantation, (2) hospitalisation because of complications after CRT device with the addition of an implantable cardioverter-defibrillator; $H F$, heart failure; $N Y H A$, New York Heart Association functional classification; $L V E F$, left ventricular ejection fraction

implantation and (3) death because of CRT implantation (or any subsequent operation). The consequent maintenance states usually referred to events like stable state (while on CRT or OPT), hospitalisation due to lead displacements or infections, hospitalisation due to HF worsening and hospitalisation due to other causes (e.g. heart transplant, CABG, ablation, etc).

All models allowed patients to move from one Markov state to another. Death states were detailed in SCD, HF death, or death from non-cardiac related (nCR) causes. In Yao et al. [12] patients that remained alive in the next time period could continue being in the same NYHA class or move to higher or lower NYHA classes. Similarly, in Bertoldi et al. [16] patients could move between NYHA classes (but with only a NHYA class at a time).

Upgrading devices from CRT-P to CRT-D was allowed in three of the selected studies [11, 15, 17]. In such cases CRT-P patients could at any time experience arrhythmia 


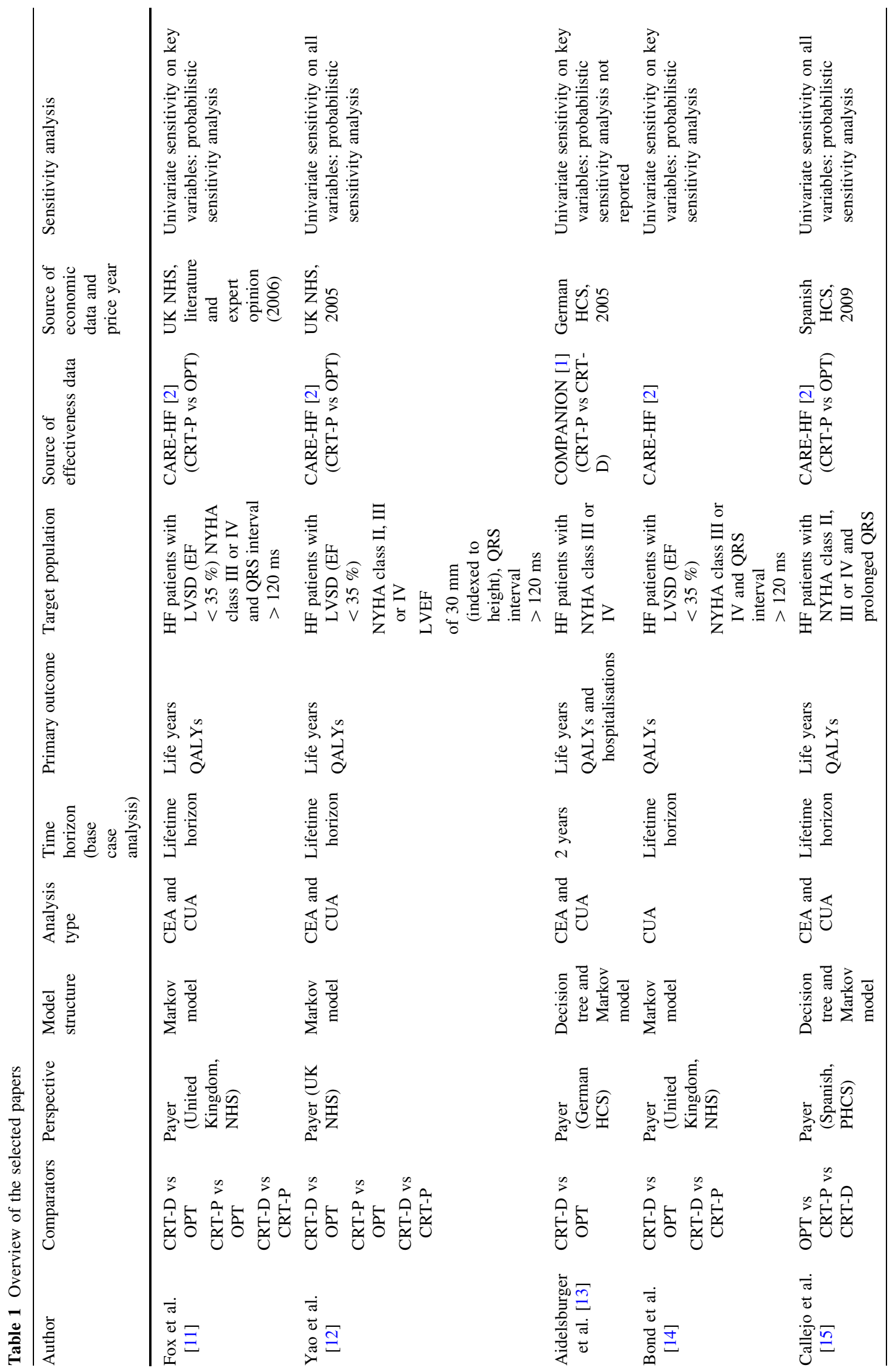




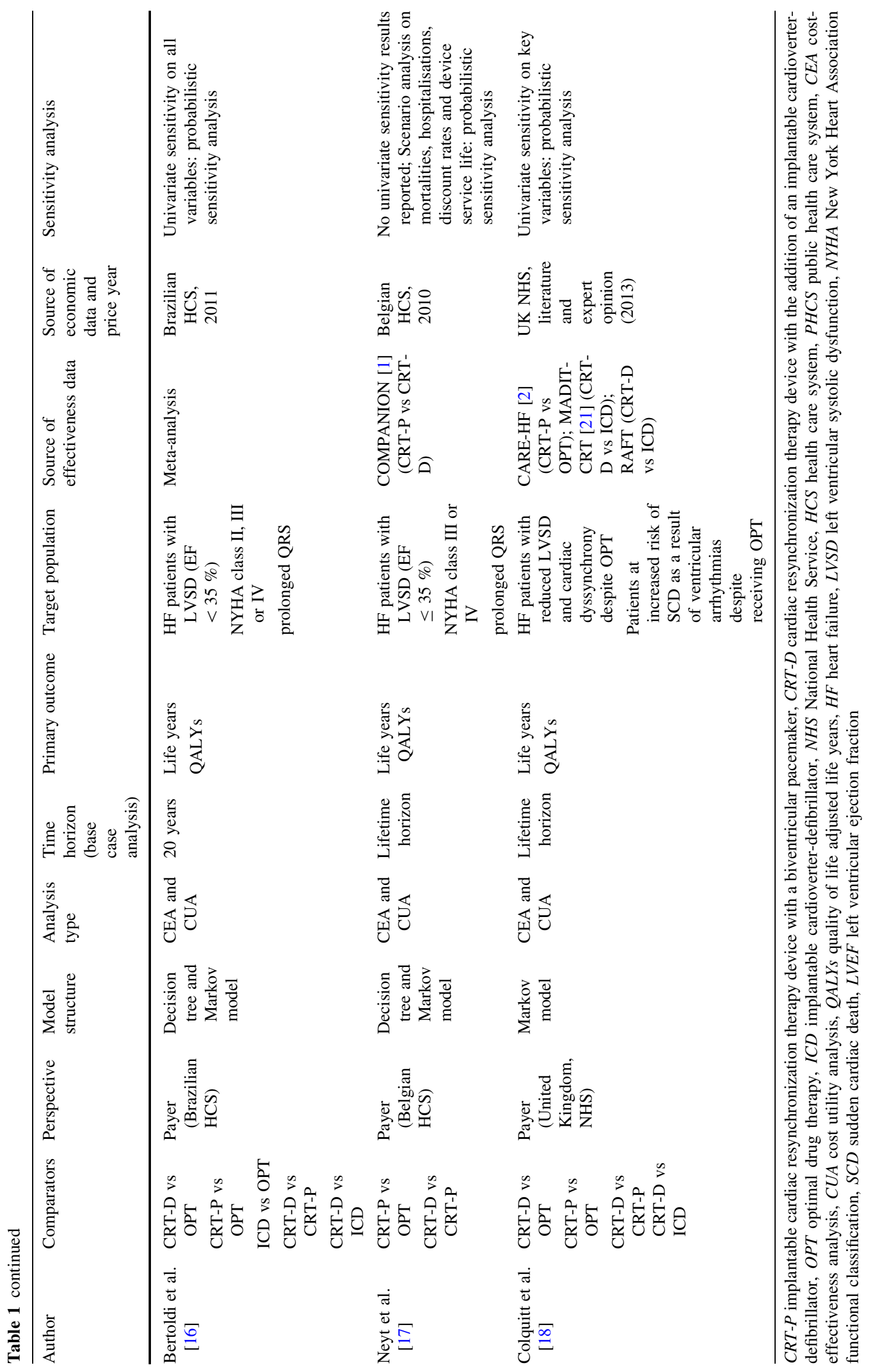


Table 2 Overview of the Markov states in the selected studies

\begin{tabular}{|c|c|c|c|c|c|c|c|c|}
\hline $\begin{array}{l}\text { Health state categories in the Markov } \\
\text { cohort models }\end{array}$ & $\begin{array}{l}\text { Fox } \\
\text { et al. } \\
\text { [11] }\end{array}$ & $\begin{array}{l}\text { Yao } \\
\text { et al. } \\
\text { [12] }\end{array}$ & $\begin{array}{l}\text { Aidelsburger } \\
\text { et al. [13] }\end{array}$ & $\begin{array}{l}\text { Bond } \\
\text { et al. [14] }\end{array}$ & $\begin{array}{l}\text { Callejo } \\
\text { et al. [15] }\end{array}$ & $\begin{array}{l}\text { Bertoldi } \\
\text { et al. [16] }\end{array}$ & $\begin{array}{l}\text { Neyt } \\
\text { et al. } \\
{[17]}\end{array}$ & $\begin{array}{l}\text { Colquitt } \\
\text { et al. [18] }\end{array}$ \\
\hline \multicolumn{9}{|l|}{ Short-term states } \\
\hline CRT-P implantation (operation) & $\sqrt{ }$ & n.a. & n.a. & $\sqrt{ }$ & $\sqrt{ }$ & n.a. & $\sqrt{ }$ & $\sqrt{ }$ \\
\hline $\begin{array}{l}\text { Complications after CRT } \\
\text { implantation }\end{array}$ & $\sqrt{ }$ & n.a. & & $\sqrt{ }$ & $\sqrt{ }$ & n.a. & & $\sqrt{ }$ \\
\hline $\begin{array}{l}\text { Death (CRT-P implantation or } \\
\text { subsequent operation) }\end{array}$ & $\sqrt{ }$ & n.a. & n.a. & $\sqrt{ }$ & $\sqrt{ }$ & n.a. & $\sqrt{ }$ & $\sqrt{ }$ \\
\hline \multicolumn{9}{|l|}{ Upgrading/switching state } \\
\hline $\begin{array}{l}\text { Upgrading CRT-P to a CRT-D } \\
\text { (operation) }\end{array}$ & $\sqrt{ }$ & & n.a. & $\sqrt{ }$ & $\sqrt{ }$ & & $\sqrt{ }$ & $\sqrt{ }$ \\
\hline ICD implantation (operation) & $\sqrt{ }$ & n.a. & n.a. & n.a. & n.a. & n.a. & $\sqrt{ }$ & $\sqrt{ }$ \\
\hline \multicolumn{9}{|l|}{ Maintenance states } \\
\hline $\begin{array}{l}\text { Patient with CRT has no adverse } \\
\text { events }^{\mathrm{a}}\end{array}$ & $\sqrt{ }$ & $\sqrt{ }$ & $\sqrt{ }$ & $\sqrt{ }$ & $\sqrt{ }$ & $\sqrt{ }$ & $\sqrt{ }$ & $\sqrt{ }$ \\
\hline $\begin{array}{l}\text { Patient receiving OPT has no adverse } \\
\text { events }^{\mathrm{a}}\end{array}$ & $\sqrt{ }$ & $\sqrt{ }$ & $\sqrt{ }$ & $\sqrt{ }$ & $\sqrt{ }$ & $\sqrt{ }$ & $\sqrt{ }$ & $\sqrt{ }$ \\
\hline $\begin{array}{l}\text { Patient with ICD has no adverse } \\
\text { events }^{\mathrm{a}}\end{array}$ & $\sqrt{ }$ & n.a. & n.a. & n.a. & n.a. & $\sqrt{ }$ & $\sqrt{ }$ & $\sqrt{ }$ \\
\hline $\begin{array}{l}\text { Hospitalization-CRT-related } \\
\text { infection }\end{array}$ & $\sqrt{ }$ & $\sqrt{ }$ & $\sqrt{ }$ & & $\sqrt{ }$ & $\sqrt{ }$ & $\sqrt{ }$ & $\sqrt{ }$ \\
\hline $\begin{array}{l}\text { Hospitalization-ICD-related } \\
\text { infection }^{\mathrm{b}}\end{array}$ & $\sqrt{ }$ & & n.a. & n.a. & n.a. & $\sqrt{ }$ & & $\sqrt{ }$ \\
\hline $\begin{array}{l}\text { (Hospitalization)—lead failure/ } \\
\text { displacement }\end{array}$ & $\sqrt{ }$ & & $\sqrt{ }$ & & $\sqrt{ }$ & $\sqrt{ }$ & & $\sqrt{ }$ \\
\hline HF hospitalisation & $\sqrt{ }$ & & $\sqrt{ }$ & $\sqrt{ }$ & $\sqrt{ }$ & $\sqrt{ }$ & & $\sqrt{ }$ \\
\hline Hospitalisation-heart transplant & $\sqrt{ }$ & $\sqrt{ }$ & $\sqrt{ }$ & & & & & $\sqrt{ }$ \\
\hline Hospitalisation-CABG & & $\sqrt{ }$ & $\sqrt{ }$ & & & & & \\
\hline $\begin{array}{l}\text { Hospitalisation-Radiofrequency } \\
\text { ablation }\end{array}$ & & $\sqrt{ }$ & $\sqrt{ }$ & & & & & \\
\hline Hospitalisation—PTCA/Stent & & $\sqrt{ }$ & $\sqrt{ }$ & & & & & \\
\hline $\begin{array}{l}\text { Maintenance of CRT (e.g. } \\
\text { device/battery change) (operation) }\end{array}$ & $\sqrt{ }$ & & & $\sqrt{ }$ & & & & $\sqrt{ }$ \\
\hline \multicolumn{9}{|l|}{ Long-term death states } \\
\hline Death from SDC & $\sqrt{ }$ & $\sqrt{ }$ & $\sqrt{ }$ & $\sqrt{ }$ & $\sqrt{ }$ & $\sqrt{ }$ & $\sqrt{ }$ & $\sqrt{ }$ \\
\hline Death from $\mathrm{HF}$ & $\sqrt{ }$ & & $\sqrt{ }$ & & $\sqrt{ }$ & $\sqrt{ }$ & & $\sqrt{ }$ \\
\hline Death from nCR causes & $\sqrt{ }$ & & $\sqrt{ }$ & & $\sqrt{ }$ & & & $\sqrt{ }$ \\
\hline
\end{tabular}

a This means that these events do not take place during the model cycle

b Yao et al. [12] include two additional states the Coronary Care Unit (CCU) and the intensive care unit (ICU)

$S D C$ Sudden Cardiac Death, $H F$ Heart failure, $n C R$ non-cardiac-related, PTCA Percutaneous Transluminal Coronary Angioplasty, n.a. not applicable

and thereafter upgrade to a CRT-D device. In addition to the above states the model by Fox et al. [11] (which consists of a synthesis of the existing models) allowed also for device explanting or replacement of the CRT-D device with a new one. Patients could also be switched to the OPT arm or get an ICD alone but only when experiencing arrhythmias or receiving a heart transplant (heart transplant state was also allowed in Colquitt [18]).

\section{Patient population}

The population considered in the selected studies were adults (aged 18 and over) eligible for CRT implantation. Eligibility criteria in all the studies were largely associated with the guidelines for CRT implantation in patients suffering from heart failure. These guidelines recommend implantation of a CRT device (with or without ICD) for 
Table 3 Values of health state utilities for the selected studies

\begin{tabular}{|c|c|c|c|c|}
\hline & Mean Utility & $95 \% \mathrm{CI}$ & Min-max values & Source \\
\hline \multicolumn{5}{|c|}{ Yao et al. [12] and Aidelsburger et al. [13] } \\
\hline NYHA class I & 0.82 & $(0.78: 0.85)$ & & [2] \\
\hline NYHA class II & 0.72 & $(0.69: 0.75)$ & & {$[2]$} \\
\hline NYHA class III & 0.59 & $(0.55: 0.63)$ & & {$[2]$} \\
\hline NYHA class IV & 0.51 & $(0.41: 0.61)$ & & {$[2]$} \\
\hline \multicolumn{5}{|c|}{ Fox et al. [11] and Bond et al. [14] } \\
\hline NYHA class I & 0.93 & & $(0.91: 0.96)$ & {$[8]$} \\
\hline NYHA class II & 0.78 & & $(0.72: 0.84)$ & {$[8]$} \\
\hline NYHA class III & 0.61 & & $(0.59: 0.63)$ & [27] \\
\hline NYHA class IV & 0.44 & & $(0.42: 0.46)$ & [27] \\
\hline \multicolumn{5}{|l|}{ Bertoldi et al. [16] } \\
\hline NYHA class I & 0.90 & & $(0.71: 0.94)$ & [28-30] \\
\hline NYHA class II & 0.83 & & $(0.61: 0.94)$ & [28-30] \\
\hline NYHA class III & 0.74 & & $(0.52: 0.84)$ & [28-30] \\
\hline NYHA class IV & 0.60 & & $(0.42: 0.74)$ & [28-30] \\
\hline \multicolumn{5}{|l|}{ Callejo et al. [15] } \\
\hline NYHA class I & 0.69 & & $(0.53 ; 0.85)$ & [31] \\
\hline NYHA class II & 0.60 & & $(0.46 ; 0.74)$ & [31] \\
\hline NYHA class III & 0.49 & & $(0.34 ; 0.64)$ & [31] \\
\hline NYHA class IV & 0.35 & & $(0.15 ; 0.55)$ & [31] \\
\hline Neyt et al. [17] & 0.78 & $(0.73: 0.83)^{\mathrm{b}}$ & & [9] \\
\hline \multicolumn{5}{|l|}{ Colquitt et al. [18] } \\
\hline NYHA class I & 0.86 & & $(0.85: 0.86)$ & [29] \\
\hline NYHA class II & 0.77 & & $(0.76: 0.78)$ & [29] \\
\hline NYHA class III & 0.67 & & $(0.73: 0.77)$ & [29] \\
\hline NYHA class IV & 0.53 & & $(0.48: 0.58)$ & \\
\hline
\end{tabular}

${ }^{a}$ Neyt et al. [17] use only mean utility values for the overall sample

b $97.5 \%$ confidence interval

Table 4 Incremental cost-effectiveness ratios (in euros per QALYs gained) ${ }^{\mathrm{a}}$

\begin{tabular}{lllll}
\hline & CRT-P versus OPT & CRT-D versus OPT & CRT-D versus CRT-P & CRT-D versus ICD \\
\hline Fox et al. [11] & $€ 20,077$ & $€ 28,372$ & $€ 48,179$ & - \\
Yao et al. [12] & $€ 6763$ & $€ 16,166$ & $€ 42,986$ & - \\
Aidelsburger et al. [13] & - & $€ 76,350$ & - & - \\
Bond et al. [14] & $€ 19,865$ & - & $€ 47,662$ & - \\
Callejo et al. [15] & $€ 30,307$ & - & $€ 56,719$ & - \\
Bertoldi et al. [16] & $€ 11,808$ & - & $€ 63,343$ & $€ 32,664$ \\
Neyt et al. [17] & $€ 9849$ & - & $€ 49,774$ & - \\
Colquitt et al. [18] & $€ 29,551^{\text {b }}$ & $€ 29,889^{\text {a }}$ & $€ 30,447^{\text {a }}$ & $€ 29,135^{\mathrm{b}}$ \\
\hline
\end{tabular}

a Indexed for purchasing power parities for GDP [26] and in 2014 prices

b Corresponds to population II in Colquitt et al. [18], i.e., patients with heart failure as a result of LVSD and cardiac dyssynchrony despite receiving OPT; Corresponds to population III in Colquitt et al. [18] i.e., group II plus patients at risk of SDC due to ventricular arrhythmias despite receiving OPT)

patients who have left ventricular ejection fraction (LVEF) $\leq 35 \%$, a QRS duration $\geq 120 \mathrm{~ms}$, sinus rhythm, and fall within NYHA functional class III or ambulatory class IV heart failure [4, 10, 19, 20]. Most of the studies complied with these criteria. Five out of the eight selected studies
$[11,12,14,15,18]$ used clinical data from the Care-HF trial, (a multicentre, international randomized trial comparing CRT-P to OPT) [2], while two other studies [13, 17] used data from the COMPANION trial (also a multicentre, international randomized trial comparing CRT-P to OPT 
Table 5 Incremental cost-effectiveness ratios (International $€$ per LYs gained) ${ }^{\mathrm{a}}$

\begin{tabular}{lllll}
\hline & CRT-P versus OPT & CRT-D versus OPT & CRT-D versus CRT-P & CRT-D versus ICD \\
\hline Fox et al. [11] & - & - & - & - \\
Yao et al. [12] & $€ 6291$ & $€ 32,179$ & $€ 32,179$ & - \\
Aidelsburger et al. [13] & - & $€ 168,040$ & - & - \\
Bond et al. [14] & - & - & - & - \\
Callejo et al. [15] & $€ 24,806$ & - & $€ 34,160$ & - \\
Bertoldi et al. [16] & $€ 22,088$ & - & $€ 46,890$ & $€ 34,054$ \\
Neyt et al. [17] & $€ 11,256$ & - & $€ 38,781$ & - \\
Colquitt et al. [18] & $€ 31,060^{\mathrm{b}}$ & $€ 13,926^{\mathrm{b}}$ & $€ 7375^{\mathrm{b}}$ & $€ 21,411^{\mathrm{b}}$ \\
\hline
\end{tabular}

${ }^{a}$ Indexed for purchasing power parities for GDP [26] and in 2014 prices

${ }^{\mathrm{b}}$ Corresponds to population II in Colquitt et al. [18], i.e., patients with heart failure as a result of LVSD and cardiac dyssynchrony despite receiving OPT; Corresponds to population III in Colquitt et al. [18] i.e., population group II in (a) plus patients at risk of SDC due to ventricular arrhythmias despite receiving OPT)

and CRT-D to OPT) [1]. Both trials used similar eligibility criteria for the selection of patients [1, 2]. Bertoldi et al. [16] used data from an outpatient clinic in a Brazilian hospital but reported a similar target population. Colquitt et al. [18] used data from the MADIT-CRT [21] and RAFT [22] trials for the comparison of CRT-D with ICD arms. Colquitt et al. [18] distinguished between three different population groups. However, for consistency with the populations of other studies, here we focus on the analysis of group II (i.e., patients with heart failure as a result of left ventricular systolic dysfunction (LVSD) and cardiac dyssynchrony despite receiving OPT) [18].

\section{Model comparators}

Six [11, 12, 14-17] out of eight selected studies included three comparators; CRT-P with OPT, CRT-D with OPT, and OPT alone. One study [13] compared only cost-effectiveness of CRT-D against CRT-P. Colquitt et al. [18] included also comparisons of ICD with OPT and CRT-D (though this was done in a different patient population).

\section{Model time horizon}

Pharmacoeconomic guidelines agree that the time horizon of a cost-effectiveness model should extend far enough in the future to capture the major health and economic outcomes, including both the intended and unintended effects [23]. With treatment for heart failure, certain treatment outcomes can be realized over a shorter period (like the outcome of the surgical intervention) while others, such as a possible effect on survival, can only be realized over a long time horizon (extending to lifetime of the patient). The duration of clinical trials testing the cardiac resynchronization therapy in heart failure disease varies from
6 months [21, 24] to 12 months [25] or to a longer period of 29 months [2]. In the selected modelling studies, patient outcomes and costs were simulated over 20 years [16] or over the complete lifetime of the patient $[11,12,14,15,17$, 18], except for one study [13] which applied a time horizon of only 2 years after implantation (Table 1). This is considered rather a conservative approach, as the high costs of implantation cannot be fully recovered within such a short term. The authors justified their choice by explaining the difficulties in the extrapolation of utilities, costs and transition probabilities beyond the 2-year follow-up of the COMPANION trial [1].

\section{Resource use and unit prices}

Resource use and unit prices in the selected studies were predominantly obtained from the health care systems of the respective countries. All the eight selected studies [11-18] employed a payer perspective. As such, they have included costs of CRT-P, CRT-D and ICD devices, costs of device implantation, lead replacement, heart failure hospitalisation and follow-up costs while in a stable health state. The level of detail varied substantially between the studies, and was predominantly dependent on the structure of the short-term or long-term models (see also above).

It should be noted that prices of devices differed between studies reflecting also the market value of the devices over time. Hence, earlier studies by Fox et al. and Yao et al. [11, 12] estimated prices of the CRT-D devices in the UK healthcare setting at respectively $€ 19,196$ and $€ 19,914$ (converted into 2014 prices in euros using OECD estimates of purchasing power parities (PPPs) for GDP [26] while the most recent study from Colquitt et al. [18] estimated this at only $€ 13,170$ (PPP adjusted and in 2014 prices). 


\section{Health state utilities}

The primary outcomes were quality-adjusted life years (QALYs) or life years (LYs). All the studies use the NYHA Functional Classification to assign the quality of life (QoL) scores for patients in each health state. Again, the only exception here is the study by Aidelsburger et al. [13] that also included hospitalisations as an outcome.

The calculation of QALYs in the selected studies was based on utility values from NYHA classes (Table 3). Seven out of eight studies [11-16, 18] distinguish between utility values for each NYHA class. Neyt et al. [17] considered mean health utilities by treatment rather than by NYHA class. They argued that this was preferred, given the substantial variation of NYHA class utility estimates between publications. In fact, health utility values used per NYHA class do vary greatly between studies, as can be seen from values in Table 3 .

\section{Cost-effectiveness results}

ICERs for cost per QALY gained and cost per LY gained are presented in Tables 4 and 5. After checking for transferability criteria [32, 33], all ICERs were converted in 2014 prices in euros using PPPs [26]. Seven out of the eight selected studies [11, 12, 14-18] reported cost-effectiveness results per QALY for CRT-P compared to OPT and for CRT-D compared to CRT-P, four studies [11-13, 18] for CRT-D compared to OPT, and two studies $[16,18]$ for CRT-D compared to ICD (Table 4). Despite the differences in ICERs, results were consistent in showing that CRT-P was mostly cost-effective in comparison to OPT alone. However, results were less clear for ICERs of CRTD compared to OPT. In the study by Aidelsburger et al. [13] this ICER was much higher than in other studies $(€ 76,350)$ which could relate to the time horizon of only 2 years in this study. In general, ICERs for CRT-D compared to CRT-P were considerably higher than for CRT-D compared to OPT. Hence, ICERs for CRT-D versus CRT-P ranged from $€ 42,986$ to $€ 63,343$ while ICERs per QALY for CRT-D versus OPT ranged from $€ 16,166$ to $€ 29,889$. The only exception was the study from Colquitt et al. [18] where both ICERs were comparable ( $€ 29,889$ vs $€ 30,447$ ), but these did not apply to the same population [18]. It should be noted that most ICERs for CRT-D versus CRT-P are well above what is considered cost-effective in most countries (for instance the $£ 20,000-£ 30,000$ threshold applied in the UK [34] - converted to €21,427-€32,139 PPP adjusted). Bertoldi et al. [16] suggested that CRT-D therapy should not be systematically recommended for CRT-P eligible patients, while it can be an option for ICD eligible patients. Yao et al. [12] suggested that CRT-D was not cost-effective, particularly for CRT-P patients with poor life expectancy. Fox et al. [11] called for more research to explore the added value of CRT-D over CRT-P and for improving identification of non-responders among patients in the CRT-D group.

Two studies [16, 18] reported ICERs for QALYs gained for CRT-D compared to ICD. Both ICERs were comparable, ranging from $€ 29,135$ to $€ 32,664$ (even though they concern different populations). Colquitt et al. [18] found such ICERs to be robust and influenced only from all-cause mortality in the ICD-only arm and lifetime of CRT-D and ICD devices [18].

Two of the selected studies [11, 14] did not report on ICERs per LY (Table 5). As for the other studies, similar trends held as in ICERs per QALY. The ICER for the comparison between CRT-D and OPT in the Aidelsburger et al. study [13] appears to be much higher than others, while ICERs for CRT-D against CRT-P remain constantly higher than ICERs for CRT-D against OPT. Again the study from Colquitt et al. [18] is an exception here, although these results should be cautiously interpreted as the population in Colquitt et al. [18] is not the same as in other studies.

\section{Uncertainty}

All selected studies [11-18] reported univariate sensitivity analysis on key variables. Key determinant variables were battery longevity [12, 13, 16, 18], cost of the device [16, 18 ] as well as relative risk for mortality from HF (for CRT$\mathrm{P}$ vs OPT or CRT-D vs CRT-P) $[14,16,18]$. Decreasing the cost of the CRT device by $50 \%$ decreased the ICERs by $23 \%$ for CRT-D vs CRT-P or by $40 \%$ for CRT-P vs OPT [16]. The selected studies assumed a base case battery life that varied from 5 [16] to 6.5 years $[14,15]$ for CRT-P devices and from $5[16,17]$ to 5.5 years $[14,15]$ for CRTD. Yao et al. [12] assumed a base case battery life of 7 years for CRT-D. Increasing battery life by $40 \%$ decreased the ICERs by more than $20 \%$ in Bertoldi et al. [16] and by $29 \%$ in Colquitt et al. [18]. The reduction of mortality with CRT-D by $13.3 \%$ decreased the ICER for CRT-D vs CRT-P by $36 \%$ [16] while the decrease in relative risk for HF death in CRT-D patients by $20 \%$ decreased the ICER by $58 \%$ [15]. Five studies reported probabilistic sensitivity analyses $[11,12,16-18]$, while one study [13] stated to have performed a two-way sensitivity analysis, but did not report the results. Four out of the eight selected studies $[11,12,17,18]$ incorporated cost-effectiveness acceptability curves (CEACs), which are used to summarize the uncertainty in the cost-effectiveness estimates. The CEACs in these four studies showed that, for a willingness-to-pay (WTP) threshold between $€ 27.000$ and $€ 44.000$ (PPP adjusted) per QALY, the probability of CRTD being cost-effective compared to OPT or CRT-P was only $26-40 \%$. 


\section{Discussion}

The review of the 6 selected economic evaluation models from January 2000 to December 2015 showed that CRT-P devices for HF patients could be considered a cost-effective therapy, if compared to OPT. However, implanting a CRT-D device instead of a CRT-P appeared much less cost-effective. Sensitivity analysis showed that cost-effectiveness of CRT-D over CRT-P depends on costs of device, battery life and relative risk for HF death in CRT-P patients. Most of the selected studies agreed that there is a need for a better identification of patients that will have a substantially improved life expectancy after implanting the CRT-D [11, 14, 15, 17].

The review showed that incremental cost-effectiveness ratios depend on characteristics of the models adopted by the selected studies. We have identified some variability in the decision models used by the selected studies. Such variability was observed around a number of methodological domains and the main assumptions used. First, the modelling approaches included both decision-trees and Markov structures. In chronic diseases Markov models are preferred over decision trees as the latter ones can get too complex over a longer time span, if they should account for switching between health states. Instead, Markov models can be more flexible and able to incorporate a series of transitions between health states over a number of discrete time periods [35-37]. However, the combination of both short-term decision trees and Markov structures in four of the selected studies allowed the different treatment strategies and various complications (associated with the implantation period) to be captured in the model. In fact, such a combination seems to be common practice in economic models of CRT for HF [11] and it is very unlikely to impact the ICERs.

We have also found that numbers of health states in the Markov structures varied between the selected studies, especially regarding the hospitalisation states. It is usually recommended that the number of states is kept as small as possible given that estimations of deterministic models using averages can cause statistical bias in average outputs [40, 41]. However, there are no reasons to believe that such differences could have been main causes behind the differences in ICERs in our selected models.

Other modelling differences in the selected studies included treatment cross-overs, (i.e. upgrading from CRT$P$ to CRT-D [11, 13-15, 17] or downgrading from CRT-D to ICD [11]) and using utility values per NYHA class [11, $12,14-16,18]$ versus the mean utility over all NYHA classes [17]. However, it is difficult to speculate on the impact these differences may have had on the ICERs.
The assumptions on the HF mortality and the hospitalisation rates of patients having a CRT-D as compared to those staying on OPT or having CRT-P alone were considered important in accurately simulating real-life events. All the selected studies in this review used data from existing clinical trials $[1,2,21]$ whose follow-up periods were much lower than the time horizon chosen in the studies. The incremental effectiveness of CRT-D after the follow-up period of the trials was maintained constant over time in all the selected studies [11-18]. This may have potentially led to an overestimation of the incremental effectiveness of CRT-D as it is likely that relative benefits of CRT-D fade out as severity of HF increases.

The assumed battery life of the pulse-generating devices was also shown to be an important determinant of the uncertainty in the cost-effectiveness estimates. The service time of the CRT-P and CRT-D devices is limited by the battery life (as battery replacement alone is not feasible and a surgical operation is needed for the replacement of the entire unit) [18]. An assumption of longer intervals for device replacement would make the CRT-D appear more cost-effective than the comparators. We found that the studies did not differ very much on this assumption, though longer service times could potentially increase the costeffectiveness of CRT-D in the future.

Additional sources of variability were differences in resource use and unit prices across the studies, differences in time horizons applied, and uncertainty around the primary efficacy of data used in the models. Resource use and unit prices may create difficulties in comparison of the results across jurisdictions [38]. Therefore, any comparison of the results in this review should be considered with caution. On the other hand, as shown here, the costs of the CRT devices tended to decrease over time even within the same country $[11,12$, 18 ] and this can be a crucial factor in determining costeffectiveness in the future.

The time horizon applied is also important as the full effects of CRT on patient survival can only be revealed over a patient's lifetime [39]. Aidelsburger et al. [13] had a much shorter life horizon, which directly impacted the ICERs of CRT-D in comparison with CRT-P. The uncertainty around the efficacy data used in the models (derived from different clinical trials or meta-analyses) hampers the interpretation of results. There was only one head-to-head comparison trial for CRT-P versus CRT-D [25]. However, this trial supported only the advantages of CRT-P over OPT and CRT-D over OPT. There is no broad consensus on the advantages of CRT-D over CRT-P, even though a meta-analysis showed some superiority of the former on all-cause death rate and cardiac death after 1-year followup [3]. Other studies pointed out that CRT-D may be 
especially beneficial to a particular group of patients, like women, those with longer QRS duration, and smaller baseline LV volumes [42]. This review noted that the ICERs for CRT-D versus CRT-P are still above what most countries are willing to pay for an additional QALY (e.g. the $£ 20,000-£ 30,000$ per QALY threshold applied in the UK [34]). It is sensible to believe that a better identification of patients for whom this technology is beneficial would reduce unavoidable costs by making CRT-D a more costeffective alternative.

\section{Conclusions}

The studies included in this review seem to converge around the finding that while CRT-P and CRT-D can be considered cost-effective if compared to OPT, cost-effectiveness of CRT-D over CRT-P remains questionable. There is no broad consensus of the relative effectiveness of CRT-D over CRT-P, and therefore studies looking at the all-cause death rate and HF death rate could prove to be important in reducing the uncertainty around cost-effectiveness results. In addition, given the high proportion of eligible patients not responding to CRT [7] or not needing the addition of an ICD [5], future studies need to better identify CRT-P patients that will have a reasonable life expectancy when treated with CRT-D. This would bring down avoidable costs, and consequently improve cost-effectiveness of CRT-D over CRT-P.

\begin{abstract}
Authors'contributions All authors contributed to the study design and coordination. F.T. performed the literature review and led development of the manuscript. A.D.I.vA contributed to manuscript development. F.P. provided an overall direction and critically reviewed the manuscript. All authors have read and approved the final manuscript.
\end{abstract}

Funding This work was supported by the Center for Translational Molecular Medicine and The Netherlands Heart Foundation under the 'Biomarkers to predict cardiac failure, arrhythmias and success of treatment' (COHFAR) project.

\section{Compliance with ethical standards}

Conflict of interest None declared.

Open Access This article is distributed under the terms of the Creative Commons Attribution 4.0 International License (http://crea tivecommons.org/licenses/by/4.0/), which permits unrestricted use, distribution, and reproduction in any medium, provided you give appropriate credit to the original author(s) and the source, provide a link to the Creative Commons license, and indicate if changes were made.

\section{Appendix: Search strategy for cost-effectiveness studies}

Medline (OvidSP) and Embase (OvidSP)

1. Cardiac pacing, artificial/

2. Pacemaker, artificial/

3. Heart-Assist Devices/

4. Heart Conduction System/

5. Defibrillators, implantable/

6. CRT-P.mp.

7. CRT-D.mp.

8. (CRT or "cardiac resynchron\$ therap\$").ti,ab.

9. (resynchroni\$ation or cardiac resynchronization therapy or biv).tw.

10. (biventricular adj2 (pacing or pacer or pacemaker or device)).tw.

11. ((implantable cardioverter-defibrillator) or (implantable cardioverter\$ adj2 defibrillator\$)).tw

12. (dual adj2 chamber adj2 (pacing or pacer or pacemaker)).tw.

13. (antitachycardia adj2 (pacing or pacemaker or pacer or device)).tw.

14. (implantable $\$$ adj2 cardioverter and defibrillator\$).ti,ab,ot,hw.

15. or/1-14

16. ((arrhythmia $\$)$ or (tachycardia\$) adj2 (ventricular or fibrillation)). ti,ab,ot,hw.

17. (heart adj4 failure).mp.

18. (left adj2 ventricular adj2 function or dysfunction).tw.

19. (ventricular adj2 tachycardia\$).tw.

20. Dyssynchrony.tw.

21. or/ $16-20$

22. economics/

23. exp "costs and cost analysis"/

24. exp "economics, hospital"/

25. economics, medical/

26. economics, nursing/

27. economics, pharmaceutical/

28. (economic $\$$ or cost or costs or costly or costing or price or prices or pricing or pharmacoeconomic $\$$ ).ti,ab.

29. (expenditure\$ not energy).ti,ab.

30. value for money.ti,ab.

31. budget $\$ . t i, a b$.

32. or/22-31

33. ((energy or oxygen) adj cost).ti,ab.

34. (metabolic adj cost).ti,ab.

35. ((energy or oxygen) adj expenditure).ti,ab. 
36. or/33-35

37. 32 not 36

38. letter.pt.

39. editorial.pt.

40. historical article.pt.

41. or $/ 38-40$

42. 37 not 41

43. Animals/

44. Humans/

45. 43 not (43 and 44)

46. 42 not 45

47. (Markov adj5 model\$).ti,ab,pt

48. (Cohort\$ simulation).tw

49. (Cost-effectiveness) .ti,ab,pt

50. Cost-effectiveness/

51. (Cost adj2 utility).ti,ab,pt

52. (Cost adj2 benefit).ti,ab,pt

53. or/47-52

54. 15 or 21

55. 54 and 46

56. 55 and 53

57. Limit 56 to $\mathrm{yr}=2000-2014$

\section{References}

1. Bristow, M.R., Feldman, A.M., Saxon, L.A.: Heart failure management using implantable devices for ventricular resynchronization: comparison of medical therapy, pacing, and defibrillation in chronic heart failure (COMPANION) trial. J. Cardiac Fail. 6(3), 276-285 (2000). doi:10.1054/jcaf.2000. 9501

2. Cleland, J.G.F., Daubert, J.-C., Erdmann, E., Freemantle, N., Gras, D., Kappenberger, L., Tavazzi, L.: The effect of cardiac resynchronization on morbidity and mortality in heart failure. N. Engl. J. Med. 352(15), 1539-1549 (2005). doi:10.1056/ NEJMoa050496

3. Jiang, M., He, B., Zhang, Q.: Comparison of CRT and CRT-D in heart failure: systematic review of controlled trials. Int. J. Cardiol. 158(1), 39-45 (2012). doi:10.1016/j.ijcard.2010.12.091

4. Epstein, A.E., DiMarco, J.P., Ellenbogen, K.A., Estes 3rd, N.A., Freedman, R.A., Gettes, L.S., Gillinov, A.M., Gregoratos, G., Hammill, S.C., Hayes, D.L., Hlatky, M.A., Newby, L.K., Page, R.L., Schoenfeld, M.H., Silka, M.J., Stevenson, L.W., Sweeney, M.O., Smith Jr, S.C., Jacobs, A.K., Adams, C.D., Anderson, J.L., Buller, C.E., Creager, M.A., Ettinger, S.M., Faxon, D.P., Halperin, J.L., Hiratzka, L.F., Hunt, S.A., Krumholz, H.M., Kushner, F.G., Lytle, B.W., Nishimura, R.A., Ornato, J.P., Riegel, B., Tarkington, L.G., Yancy, C.W.: ACC/AHA/HRS 2008 guidelines for device-based therapy of cardiac rhythm abnormalities: a report of the American College of Cardiology/American Heart Association Task Force on Practice Guidelines (writing committee to revise the ACC/AHA/NASPE 2002 guideline update for implantation of cardiac pacemakers and antiarrhythmia devices) developed in collaboration with the American Association for Thoracic Surgery and Society of Thoracic Surgeons. J. Am. Coll. Cardiol. 51(21), e1-e62 (2008)
5. Jeevanantham, V., Daubert, J.P., Zareba, W.: Cardiac resynchronization therapy in heart failure patients: an update. Cardiol. J. 16(3), 197-209 (2009)

6. Kang, S., Cannom, D.: Current role of device therapy to reduce sudden cardiac death in heart failure. Curr. Heart Fail. Rep. 1(3), 104-110 (2004). doi:10.1007/s11897-004-0019-2

7. McAlister, F.A., Ezekowitz, J., Hooton, N., et al.: Cardiac resynchronization therapy for patients with left ventricular systolic dysfunction: a systematic review. JAMA 297(22), 2502-2514 (2007). doi:10.1001/jama.297.22.2502

8. Calvert, M.J., Freemantle, N., Cleland, J.G.F.: The impact of chronic heart failure on health-related quality of life data acquired in the baseline phase of the CARE-HF study. Eur. J. Heart Fail. 7(2), 243-251 (2005). doi:10.1016/j.ejheart. 2005.01.012

9. Feldman, A.M., de Lissovoy, G., Bristow, M.R., Saxon, L.A., De Marco, T., Kass, D.A., Boehmer, J., Singh, S., Whellan, D.J., Carson, P., Boscoe, A., Baker, T.M., Gunderman, M.R.: Cost effectiveness of cardiac resynchronization therapy in the comparison of medical therapy, pacing, and defibrillation in heart failure (COMPANION) trial. J. Am. Coll. Cardiol. 46(12), 2311-2321 (2005). doi:10.1016/j.jacc.2005.08.033

10. Tracy, C.M., Epstein, A.E., Darbar, D., DiMarco, J.P., Dunbar, S.B., Estes, N.A.M., Ferguson, T.B., Hammill, S.C., Karasik, P.E., Link, M.S., Marine, J.E., Schoenfeld, M.H., Shanker, A.J., Silka, M.J., Stevenson, L.W., Stevenson, W.G., Varosy, P.D.: 2012 ACCF/AHA/HRS focused update of the 2008 guidelines for device-based therapy of cardiac rhythm abnormalities: a report of the American College of Cardiology Foundation/American Heart Association Task Force on Practice Guidelines. J. Am. Coll. Cardiol. 60(14), 1297-1313 (2012). doi:10.1016/j.jacc.2012.07. 009

11. Fox, M., Mealing, S., Anderson, R., Dean, J., Stein, K., Price, A., Taylor, R.S.: The clinical effectiveness and cost-effectiveness of cardiac resynchronisation (biventricular pacing) for heart failure: systematic review and economic model. Health Technol Assess 11(47), iii-iv, ix-248 (2007)

12. Yao, G., Freemantle, N., Calvert, M.J., Bryan, S., Daubert, J.-C., Cleland, J.G.F.: The long-term cost-effectiveness of cardiac resynchronization therapy with or without an implantable cardioverter-defibrillator. Eur. Heart J. 28(1), 42-51 (2007). doi:10. 1093/eurheartj/ehl382

13. Aidelsburger, P., Grabein, K., Klauss, V., Wasem, J.: Cost-effectiveness of cardiac resynchronization therapy in combination with an implantable cardioverter defibrillator (CRT-D) for the treatment of chronic heart failure from a German health care system perspective. Clin. Res. Cardiol. 97(2), 89-97 (2008). doi:10.1007/s00392-007-0586-9

14. Bond, M., Mealing, S., Anderson, R., Dean, J., Stein, K., Taylor, R.S.: Is combined resynchronisation and implantable defibrillator therapy a cost-effective option for left ventricular dysfunction? Int. J. Cardiol. 137(3), 206-215 (2009)

15. Callejo, D., Guerra, M., Hernández-Madrid, A., Blasco, J.A.: Economic assessment of cardiac resynchronization therapy. Rev. Esp. Cardiol. 63(11), 1235-1243 (2010)

16. Bertoldi, E.G., Rohde, L.E., Zimerman, L.I., Pimentel, M., Polanczyk, C.A.: Cost-effectiveness of cardiac resynchronization therapy in patients with heart failure: the perspective of a middleincome countryss public health system. Int. J. Cardiol. (2011). doi:10.1016/j.ijcard.2011.06.046

17. Neyt, M., Stroobandt, S., Obyn, C., Camberlin, C., Devriese, S., De Laet, C., Van Brabandt, H.: Cost-effectiveness of cardiac resynchronisation therapy for patients with moderate-to-severe heart failure: a lifetime Markov model. BMJ Open 1(2), e000276 (2011). doi:10.1136/bmjopen-2011-000276 
18. Colquitt, J.L., Mendes, D., Clegg, A.J., Harris, P., Cooper, K., Picot, J., Bryant, J.: Implantable cardioverter defibrillators for the treatment of arrhythmias and cardiac resynchronisation therapy for the treatment of heart failure: systematic review and economic evaluation. Health Technol. Assess. 18(56), 1-559 (2014)

19. Dickstein, K., Vardas, P.E., Auricchio, A., Daubert, J.-C., Linde, C., McMurray, J., Ponikowski, P., Priori, S.G., Sutton, R., van Veldhuisen, D.J., Guidelines, E.C.F.P., Vahanian, A., Auricchio, A., Bax, J., Ceconi, C., Dean, V., Filippatos, G., Funck-Brentano, C., Hobbs, R., Kearney, P., McDonagh, T., Popescu, B.A., Reiner, Z., Sechtem, U., Sirnes, P.A., Tendera, M., Vardas, P., Widimsky, P., Reviewers, D., Tendera, M., Anker, S.D., Blanc, J.-J., Gasparini, M., Hoes, A.W., Israel, C.W., Kalarus, Z., Merkely, B., Swedberg, K., Camm, A.J.: 2010 Focused update of ESC guidelines on device therapy in heart failure: an update of the 2008 ESC guidelines for the diagnosis and treatment of acute and chronic heart failure and the 2007 ESC guidelines for cardiac and resynchronization therapy developed with the special contribution of the Heart Failure Association and the European Heart Rhythm Association. Eur. Heart J. 31(21), 2677-2687 (2010). doi:10.1093/eurheartj/ehq337

20. Brignole, M., Auricchio, A., Baron-Esquivias, G., Bordachar, P., Boriani, G., Breithardt, O.-A., Cleland, J., Deharo, J.-C., Delgado, V., Elliott, P.M., Gorenek, B., Israel, C.W., Leclercq, C., Linde, C., Mont, L., Padeletti, L., Sutton, R., Vardas, P.E., Zamorano, J.L., Achenbach, S., Baumgartner, H., Bax, J.J., Bueno, H., Dean, V., Deaton, C., Erol, C., Fagard, R., Ferrari, R., Hasdai, D., Hoes, A.W., Kirchhof, P., Knuuti, J., Kolh, P., Lancellotti, P., Linhart, A., Nihoyannopoulos, P., Piepoli, M.F., Ponikowski, P., Sirnes, P.A., Tamargo, J.L., Tendera, M., Torbicki, A., Wijns, W., Windecker, S., Kirchhof, P., BlomstromLundqvist, C., Badano, L.P., Aliyev, F., Bänsch, D., Baumgartner, H., Bsata, W., Buser, P., Charron, P., Daubert, J.-C., Dobreanu, D., Faerestrand, S., Hasdai, D., Hoes, A.W., Le Heuzey, J.-Y., Mavrakis, H., McDonagh, T., Merino, J.L., Nawar, M.M., Nielsen, J.C., Pieske, B., Poposka, L., Ruschitzka, F., Tendera, M., Van Gelder, I.C., Wilson, C.M.: 2013 ESC guidelines on cardiac pacing and cardiac resynchronization therapy, vol. 34. The Task Force on Cardiac Pacing and Resynchronization Therapy of the European Society of Cardiology (ESC). Developed in collaboration with the European Heart Rhythm Association (EHRA), vol. 29 (2013)

21. Moss, A.J., Hall, W.J., Cannom, D.S., Klein, H., Brown, M.W., Daubert, J.P., Estes, N.A.M., Foster, E., Greenberg, H., Higgins, S.L., Pfeffer, M.A., Solomon, S.D., Wilber, D., Zareba, W.: Cardiac-resynchronization therapy for the prevention of heartfailure events. N. Engl. J. Med. 361(14), 1329-1338 (2009). doi:10.1056/NEJMoa0906431

22. Pinter, A., Mangat, I., Korley, V., Connolly, S., Connors, S., Gardner, M., Philippon, F., Sterns, L., Thibault, B., Dorian, P.: Assessment of resynchronization therapy on functional status and quality of life in patients requiring an implantable defibrillator. Pacing Clin. Electrophysiol. 32(12), 1509-1519 (2009). doi:10. 1111/j.1540-8159.2009.02543.x

23. Gold, M.R., Siegel, J.E., Russell, L.B., Weinstein, M.C. (eds.): Cost effectiveness in health and medicine. Oxford University Press, Oxford (1996)

24. Greenberg, D., Katz, A., Epstein, M., Golovchiner, G., Ilia, R., Caspi, A.: Implantable cardioverter defibrillators in Israel: utilization and implantation trends. Int. J. Cardiol. 82(1), 17-23 (2002)

25. Bristow, M.R., Saxon, L.A., Boehmer, J., Krueger, S., Kass, D.A., De Marco, T., Carson, P., DiCarlo, L., DeMets, D., White, B.G., DeVries, D.W., Feldman, A.M.: Cardiac-resynchronization therapy with or without an implantable defibrillator in advanced chronic heart failure. N. Engl. J. Med. 350(21), 2140-2150 (2004). doi:10.1056/NEJMoa032423

26. OECD: Purchasing power parities for GDP and related indicators. http://stats.oecd.org/Index.aspx?DataSetCode=PPPGDP (data extracted on 17 Feb 2014 10:19 UTC (GMT) from OECD.Stat). http://stats.oecd.org/Index.aspx?DataSetCode=PPPGDP (2014). Accessed Oct 2013

27. Kirsch, J., McGuire, A.: Establishing health state valuations for disease specific states: an example from heart disease. Health Econ. 9(2), 149-158 (2000). doi:10.1002/(sici)10991050(200003)9:2<149:aid-hec501>3.0.co;2-n

28. Ezekowitz, J.A., Rowe, B.H., Dryden, D.M., Hooton, N., Vandermeer, B., Spooner, C., McAlister, F.A.: Systematic review: implantable cardioverter defibrillators for adults with left ventricular systolic dysfunction. Ann. Intern. Med. 147(4), 251-262 (2007)

29. Gohler, A., Geisler, B.P., Manne, J.M., Kosiborod, M., Zhang, Z., Weintraub, W.S., Spertus, J.A., Gazelle, G.S., Siebert, U., Cohen, D.J.: Utility estimates for decision - analytic modeling in chronic heart failure-health states based on New York Heart Association classes and number of rehospitalizations. Value Health 12(1), 185-187 (2009). doi:10.1111/j.1524-4733.2008.00425.x

30. Miller, G., Randolph, S., Forkner, E., Smith, B., Galbreath, A.D.: Long-term cost-effectiveness of disease management in systolic heart failure. Med. Decis. Mak. 29(3), 325-333 (2009). doi:10. 1177/0272989x08327494

31. Rivas, B., Permanyer-Miralda, G., Brotons, C., Aznar, J., Sobreviela, E.: Health-related quality of life in unselected outpatients with heart failure across Spain in two different health care levels. Magnitude and determinants of impairment: the INCA study. Qual. Life Res. 17(10), 1229-1238 (2008). doi:10. 1007/s11136-008-9397-3

32. Drummond, M., Barbieri, M., Cook, J., Glick, H.A., Lis, J., Malik, F., Reed, S.D., Rutten, F., Sculpher, M., Severens, J.: Transferability of economic evaluations across jurisdictions: ISPOR Good Research Practices Task Force report. Value Health Reg. Issues 12(4), 409-418 (2009). doi:10.1111/j.1524-4733. 2008.00489.x

33. Welte, R., Feenstra, T., Jager, H., Leidl, R.: A decision chart for assessing and improving the transferability of economic evaluation results between countries. PharmacoEconomics 22(13), 857-876 (2004). doi:10.2165/00019053-200422130-00004

34. McCabe, C., Claxton, K., Culyer, A.J.: The NICE cost-effectiveness threshold: what it is and what that means. Pharmacoeconomics 26(9), 733-744 (2008)

35. Sonnenberg, F.A., Beck, J.R.: Markov models in medical decision making: a practical guide. Med. Decis. Mak. 13(4), 322-338 (1993). doi:10.1177/0272989x9301300409

36. Briggs, A., Sculpher, M.: An introduction to Markov modelling for economic evaluation. PharmacoEconomics 13(4), 397-409 (1998). doi:10.2165/00019053-199813040-00003

37. Briggs, A., Claxton, K., Sculpher, M.: Decision modelling for health economic evaluation. Oxford University Press Inc., New York (2006)

38. Cowie, M.R., Marshall, D., Drummond, M., Ferko, N., Maschio, M., Ekman, M., de Roy, L., Heidbuchel, H., Verboven, Y., Braunschweig, F., Linde, C., Boriani, G.: Lifetime cost-effectiveness of prophylactic implantation of a cardioverter defibrillator in patients with reduced left ventricular systolic function: results of Markov modelling in a European population. Europace 11(6), 716-726 (2009)

39. Foley, P.W.X., Leyva, F., Frenneaux, M.P.: What is treatment success in cardiac resynchronization therapy? Europace 11(suppl 5), v58-v65 (2009). doi:10.1093/europace/eup308 
40. Sculpher, M., Fenwick, E., Claxton, K.: Assessing quality in decision analytic cost-effectiveness models. PharmacoEconomics 17(5), 461-477 (2000)

41. Brennan, A., Chick, S.E., Davies, R.: A taxonomy of model structures for economic evaluation of health technologies. Health Econ. 15(12), 1295-1310 (2006)

42. Gold, M.R., Tsintzos, S.I., Sidhu, M.K., Mealing, S., Fortier, K.A., Padhiar, A., Abraham, W.T.: Economic impact and cost- effectiveness of cardiac resynchronization therapy versus optimal medical therapy in mild heart failure: long-term follow-up and projections from reverse. Circulation, 128(22 Supplement), A11299 (2013) 